\title{
Role of safe space in improving menstrual awareness and menstrual hygiene practices among adolescents in Zamfara: a case study of REACH project intervention
}

\section{Yakubu Lawali ${ }^{1 *}$, Murtala Bello², Rahinatu Adamu Hussaini ${ }^{3}$, Chanan Solomon Jongshwan ${ }^{3}$}

${ }^{1}$ Department of Nursing, College of Health Sciences

${ }^{2}$ Zamfara Ministry of Health

${ }^{3}$ Save the Children International, Nigeria

Received: 05 October 2021

Revised: 14 November 2021

Accepted: 15 November 2021

\section{*Correspondence:}

Dr. Yakubu Lawali,

E-mail: lawaliyakubu@yahoo.com

Copyright: () the author(s), publisher and licensee Medip Academy. This is an open-access article distributed under the terms of the Creative Commons Attribution Non-Commercial License, which permits unrestricted non-commercial use, distribution, and reproduction in any medium, provided the original work is properly cited.

\section{ABSTRACT}

Background: Menstrual awareness and hygiene practices have been a challenge for adolescent girls in African countries and Nigeria inclusive which subsequently affects their health, and wellbeing. The aim of the study was to evaluate the effects of REACH project intervention in improving knowledge and practice of menstrual care among adolescent girls.

Methods: A post-test only non-equivalent groups quasi-experimental design was adopted with Kaura Namoda and Talata Mafara as the intervention Local Government Authorities (LGAs) and Bungudu and Maru as the control LGAs conducted between August 2021 to October 2021. Quantitative approach was employed using self-developed questionnaire for data collection. Multi-stage sampling technique was used. A total of 400 questionnaires were administered with 200 each for control and intervention LGAs.

Results: The result of the study shows that, adolescents in the REACH Project intervention communities have higher level of awareness and more likely to practice menstrual hygiene as compared to non-REACH intervention communities. Therefore, it is recommended that, safe space strategies should be adopted in any matters related to adolescents sexual and reproductive health.

Conclusions: Safe space is effective in improving adolescents sexual and reproductive health.

Keywords: Adolescents, REACH, Menstruation, Hygiene, Awareness, Practice

\section{INTRODUCTION}

Adolescence is a transition period from childhood to adulthood life during which secondary sexual characteristics take place. Hormonal changes in this stage of life lead to an accelerated transformation which include rapid physical, cognitive, and psychosocial growth. ${ }^{1}$ As part of the physiological changes menstruation is the natural event which involves monthly loss of blood from the private part of adolescents. ${ }^{2}$ According to United Nation Children's' Fund (UNICEF), as a normal phenomenon, menstruation still is bounded by several misbeliefs or misconceptions and girls do not feel free to discuss it with other individuals in the public, classroom and even it can be a great taboo to discuss in the family. ${ }^{3}$

Studies from many low-income countries show that many girls start menstruation without any preparation for it and does not know the reason and normalcy of the monthly bleeding4. This lead to stress, confusion, shame, and fear among adolescents due to a lack of knowledge and poor menstrual hygiene practices. ${ }^{4,5}$ Additionally, there is a 
report of teasing and harassment from boys and classmates, not standing in class to answer questions, concerns about odour, and an embarrassing menstrual leak in the classroom among adolescent girls. ${ }^{6}$

Moreover, adolescent girls reported menstrual pain and lack of effective materials for safe menstrual hygiene practices as a reason for not going to schools. ${ }^{6}$ As a result, they were reported frequently using folded, bunched up, or sewed cloth, tissues, or toilet paper, scraps of old cloth, or strips of an old blanket, which often leak and made school attendance difficult. ${ }^{7}$

Despite increasing local and global attention to menstrual hygiene practice and its impact on adolescent girls as part of ASRH, substantial knowledge gaps exists. ${ }^{7}$ Menstruation and menstrual hygiene practice continue to be a monthly challenge for women and girls across Nigeria.

In line with the global effort to improve sexual and reproductive health of adolescents, REACH Project was implemented. The project adopted a safe space approach in creating awareness about sexual and reproductive health among adolescents in Zamfara, Katsina and Gombe states.

Although few studies highlighted the level of knowledge on menstruation and menstrual hygiene practice among school adolescent girls in Nigeria, that has not been established in the Zamfara, katsina and Gombe states where REACH project was implemented. Therefore, this study will evaluate the effects of the REACH project safe space approach on menstruation and practice.

\section{METHODS}

\section{Study type}

A post-test only non-equivalent groups quasi-experimental design was adopted. Quantitative approach was employed using self-developed questionnaire for data collection. Multi-stage sampling technique was used where 2 LGAs were randomly selected to compare with the 2 implementing LGAs. Each LGA was divided into ten wards. list of the communities was obtained and one community from each ward was randomly selected by lottery method and from each community ten (10) participants were taken using systematic sampling to complete 400 samples size. (4 LGAs, 40 wards, 40 communities).

\section{Instrument for data collection}

For the data collection, self-developed questionnaire was used. 200 for the intervention group (Talata Mafara and Kaura Namoda) and 200 for the Control Group (Bungudu and Maru). The questionnaire has three sections; Section A deals with the demographic information of the respondents, Section $\mathrm{B}$ has 13 questions, testing the awareness of individual about menstruation and menstrual hygiene practice and Section C has 12 questions, it captures the adolescent practice towards monthly periods (menstrual hygiene practice)

\section{Validity}

The questionnaire was submitted for review by panel of 5 experts on ASRH for face and content validity. For content validity ratio, (CVR) each item was assessed by the panel using a 3-point scale (essential, useful but not essential, not necessary). The feedback received and CVR was calculated using Lawshe (1975), method: $C V R=$ ne(N/2)/N/2 For awareness section the CVR is 1.2 (minimum acceptable value is 0.99 for 5 panel) while CVR for practice was 1.1.

\section{Reliability}

Crombach alpha obtained from the pilot study as the internal consistency reliability measure with 10 adolescents was 0.85 for awareness and 0.74 for practice.

\section{Study place}

The study is conducted in zamfara as part of the REACH project implementation state. The four Local Government Authorities (LGAs) were chosen and these are Kaura Namoda and Talata Mafara as the intervention Local Government Authorities (LGAs) and Bungudu and Maru as the control LGAs.

\section{Study period}

The study is conducted between August 2021 to October 2021.

\section{Selection criteria}

The adolescent include in the study are those who graduated from REACH project safe spaces (for intervention LGAs), between the ages of 15-19, girls and live in Zamfara.

\section{Procedure}

Respondents were recruited based on the inclusion criteria. Those in the intervention group were traced through the graduating register and contacted for their willingness to take part. Those who agreed were given consent form to sign or sign for. Two LGAs were randomly selected to compare with the 2 implementing LGAs. Each LGA was divided into ten wards. list of the communities was obtained and one community from each ward was randomly selected by lottery method and from each community ten participants were taken using systematic sampling to complete 400 samples size. (4 LGAs, 40 wards, 40 communities). In each committee the village heads were informed and take part in mobilization of respondents. Snacks were given to the respondents after responding to the questionnaire. 


\section{Ethical approval}

This is obtained from ethical committee of ministry of health Zamfara state.

\section{Statistical analysis}

The data was analysed using Statistical package for social sciences (SPSS) version 22. This included descriptive statistics and inferential statistics. Independent and paired t-test statistical tests were run.

\section{RESULTS}

The table above shows that majority of the respondents $301(75.25 \%)$ are between the age of 15-17 and are majorly Muslim by religion 385 (96.25).

Table 1: Demographic characteristics.

\begin{tabular}{|llll|}
\hline Variables & Category & Number & Percentage \\
\hline Respondents & $15-17$ & 301 & 75.25 \\
\cline { 2 - 4 } age in Years & $18-19$ & 99 & 24.75 \\
\hline \multirow{2}{*}{ Religion } & Islam & 385 & 96.25 \\
\cline { 2 - 4 } & Christian & 15 & 3.75 \\
\hline \multirow{2}{*}{$\begin{array}{l}\text { Educational } \\
\text { Level }\end{array}$} & Primary & 229 & 57.25 \\
\cline { 2 - 4 } & Secondary & 74 & 18.5 \\
\cline { 2 - 4 } Marital & Islamiyah & 97 & 24.25 \\
\hline \multirow{2}{*}{\begin{tabular}{l} 
Status \\
\cline { 2 - 4 }
\end{tabular}} & Unmarried & 332 & 83 \\
\cline { 2 - 4 } & Married & 63 & 15.75 \\
\hline
\end{tabular}

Table 2: Awareness of adolescents about mensuration and menstrual practice.

\begin{tabular}{|lll|}
\hline & $\begin{array}{l}\text { Awareness of } \\
\text { Adolescents } \\
\text { in REACH } \\
\text { implementin } \\
\text { g LGAs }\end{array}$ & $\begin{array}{l}\text { Menstrual } \\
\text { hygiene } \\
\text { Practice In } \\
\text { REACH } \\
\text { implementing } \\
\text { LGAs }\end{array}$ \\
\hline $\mathbf{N}$ Valid & 200 & 200 \\
\hline Mean & 0 & 0 \\
\hline Median & 3.7831 & 0.7892 \\
\hline Mode & 3.7692 & 0.8333 \\
\hline Std. Deviation & 3.77 & 0.83 \\
\hline Variance & .16481 & 0.09704 \\
\hline
\end{tabular}

Cut off mean: $0-.9=$ No awareness, $1-1.9=$ low awareness, 2-2.9 = moderate awareness, 3-4=high level awareness. Good practice $=0.5-1.0$, poor practice $=0.0-0.49$

In the table 1 , the mean awareness of adolescents is 3.78 which indicate high level awareness of menstruation. Similarly, the menstrual hygiene practice is also good as shown in the table with a mean of 0.7892 .
The table 2 that, significant difference exists between REACH and Non-REACH implementing communities in terms of awareness of menstrual hygiene practice. Therefore, the null hypothesis is rejected $(p=0.000)$. Similarly, statistical difference exists in terms of practice of menstrual hygiene practice among adolescents in the two groups $(\mathrm{p}=000)$. This can be evaluated as having high level awareness of adolescents in the REACH implementing communities as compared to non-REACH implementing communities.

Table 3: Group statistics for independent sample ttest.

\begin{tabular}{|c|c|c|c|c|c|}
\hline & Group & $\mathbf{N}$ & $\begin{array}{l}\text { Me } \\
\text { an }\end{array}$ & SD & $\begin{array}{l}\mathbf{P} \\
\text { value }\end{array}$ \\
\hline \multirow{2}{*}{$\begin{array}{l}\text { Menstruati } \\
\text { on } \\
\text { Awareness }\end{array}$} & RIC & 200 & $\begin{array}{l}3.7 \\
831\end{array}$ & $\begin{array}{l}0.164 \\
81\end{array}$ & \multirow{2}{*}{0.000} \\
\hline & NRIC & 200 & $\begin{array}{l}3.2 \\
488\end{array}$ & $\begin{array}{l}0.648 \\
42\end{array}$ & \\
\hline \multirow{2}{*}{$\begin{array}{l}\text { Adolescent } \\
\text { menstrual } \\
\text { hygiene } \\
\text { Practice }\end{array}$} & RIC & 200 & $\begin{array}{l}0.7 \\
892\end{array}$ & $\begin{array}{l}0.097 \\
04\end{array}$ & \multirow{2}{*}{0.000} \\
\hline & NRIC & 200 & $\begin{array}{l}0.5 \\
842\end{array}$ & $\begin{array}{l}0.213 \\
48\end{array}$ & \\
\hline
\end{tabular}

\section{DISCUSSION}

From the findings of the study, the $75.25 \%$ of the respondents are between the age of 15-17 years and 96.25\% are Muslim by religion. $57.25 \%$ finished primary school. Majority (83\%) are unmarried. This could be as a result of the majority are between the ages of 15 and 17 .

On the side of awareness of the adolescents in REACH Project intervention communities (graduates of safe space sessions), the study establishes high level awareness of menstruation and menstrual hygiene among adolescents $(\mathrm{X}=3.78, \mathrm{SD}=0.16481)$.

Similarly, for the menstrual hygiene practice, the study found the adolescents who attended safe space sessions to be $\operatorname{good}(\mathrm{X}=0.7892, \mathrm{SD}=0.09704)$. Similarly, Gizachew, In his study revealed three-fourth of adolescents had good overall knowledge but two-third of them had inadequate menstrual health practice. ${ }^{9}$ In similar study identify about $50 \%$ of the respondents do not have Knowledge about the organ from where bleeding occurs. ${ }^{10}$ The finding of the current study is in agreement with the findings of Birhane and Serbessa, in Ethiopia where the menstrual hygiene practice was found to be good among adolescent girls. ${ }^{8}$

For the level of awareness of menstruation and menstrual hygiene, between REACH project intervention and nonintervention communities, the study establishes the relationships to be statistically significant and thereby rejecting the null hypothesis $(\mathrm{p}=0.000)$. This shows that, adolescents who attended safe space sessions are more aware about menstruation and menstrual hygiene practice $(\mathrm{p}=0.000, \mathrm{X}=3.78, \mathrm{SD}=0.16481)$, than those who did not 
$(\mathrm{X}=3.2488, \mathrm{SD}=0.64842)$. However, in a study conducted in India10, shows that, majority $(60 \%)$ of the adolescents in the rural areas still believe in superstitions as relate to menstrual hygiene practice. The same study also reported that, majority $(77 \%)$ of the adolescent girls did not change their pads or cloths more than two times during menstruation and hence indicated low hygiene practice during menstruation. As it relates to this study and the outcome of REACH project intervention, it is clear that safe space can be used in providing information regarding ASRH and that can lead to good menstrual hygiene practice.

\section{Limitation}

The study limitation is that of not able to take pre-test data of the control group. It is also limited to Zamfara without including other REACH project implementing LGAs.

\section{CONCLUSION}

Safe space is effective in improving adolescents sexual and reproductive health.

\section{ACKNOWLEDGMENTS}

Acknowledge the funding provided by the GAC Canada and wonderful support by the SCI, Nigeria.

Funding: No funding sources Conflict of interest: None declared

Ethical approval: The study was approved by the Institutional Ethics Committee

\section{REFERENCES}

1. Savi-çakar F, Tagay Ö, Ebru Ikiz F. Risky behaviors of adolescents: definitions and prevention. In: Columbus AM, editor. Advances in Psychology Research. Nova Science Publishers. 2015;106(2):13767.

2. Swenson I, Havens B. Menarche and menstruation: a review of the literature. J Community Health Nurs. 1987;4(4):199-210.
3. UNICEF WASH. Menstrual hygiene management in ethiopia national baseline report from six regions of Ethiopia. Addis Ababa, Ethiopia; 2017. Available at: https://www.unicef.org/ethiopia/media/3096/file/Me nstrualHygieneManagementinEthiopia.pdf. Accessed on 24 February 2021.

4. Belayneh Z, Mekuriaw B. Knowledge and menstrual hygiene practice among adolescent school girls in southern Ethiopia: a cross-sectional study. BMC Public Health. 2019;19(1):1595.

5. Fatusi OA, Hindin MJ. Adolescents and youth in developing countries: health and development issues in context. J Adolesc. 2010;33(4):499-508.

6. WHO. Orientation programme on adolescent health for health-care providers [Internet]. Geneva, Switzerland; 2018: 6. Available at: https://www.who.int/maternal_child_adolescent/docu ments/pdfs/9241591269_op_handout.pdf. Accessed on 24 February 2021.

7. Mcmahon SA, Winch PJ, Caruso BA. The girl with her period is the one to hang her head ' reflections on menstrual management among schoolgirls in rural Kenya. BMC Int Health Hum Rights. 2011;11(1):7.

8. Miiro G, Rutakumwa R, Nakiyingi-Miiro J. Menstrual health and school absenteeism among adolescent girls in Uganda (MENISCUS): a feasibility study. BMC Womens Health. 2018;18(1):1-13.

9. Sommer M, Sahin M. Advancing the global agenda for menstrual hygiene management for schoolgirls. Am J Public Health. 2013;103(9):1556-9.

10. Birhane AD, Serbessa MK, Degfie TT. Menstrual hygiene management: a study of adolescent schoolgirls in sebeta town, oromia region, Ethiopia. Glob Drugs Ther. 2020;5:1-8.

11. Deepa A, Geetha R. A Study on Menstruation and Personal Hygiene among Adolescent Girls; International Journal of Current Microbiology and Applied Sciences. 2019;8:2319-7706.-21.

Cite this article as: Lawali Y, Bello M, Hussaini R, Jongshwan CS. Role of safe space in improving menstrual awareness and menstrual hygiene practices among adolescents in Zamfara: a case study of REACH project intervention. Int J Reprod Contracept Obstet Gynecol 2021;10:4388-91. 